\title{
Spontaneous expectoration of lung tumour mass
}
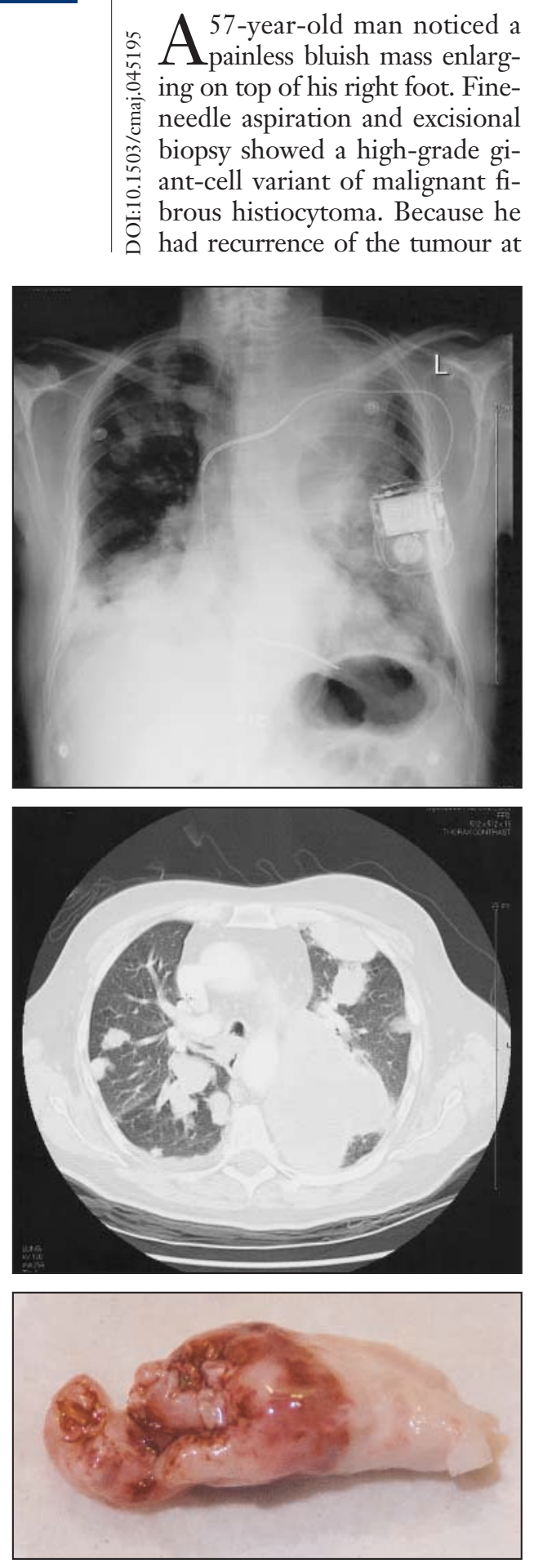

the initial excision site within 2 months, the patient opted for below-knee amputation without adjuvant radiation therapy. The surgical resection margins were free of tumour cells.

Unfortunately, the patient had increasing shortness of breath on exertion within 4 months after amputation. A chest CT showed bilateral pulmonary nodules consistent with metastases. He was admitted to hospital 5 months after the onset of shortness of breath for anthracycline-based chemotherapy. However, his left ventricular ejection fraction decreased, and therapy was switched to an ifosfamide-based regimen. Despite this, serial imaging showed enlarging nodules in the lung (Fig. 1 and Fig. 2 ), and hemoptysis developed 16 months after the start of chemotherapy. Along with bright red blood, the patient coughed up solid masses up to $5 \mathrm{~cm}$ in length (Fig. 3). Biopsy of the expectorated masses confirmed the radiologic diagnosis of metastatic malignant fibrous histiocytoma to the lung. The patient died in hospital within 2 months after the onset of hemoptysis.

Malignant fibrous histiocytoma is the most common soft-tissue sarcoma in adults, ${ }^{1}$ occurring most often in the lower extremities. The tumour contains both histiocyte and fibroblast-like cells. There are many histologic subtypes, around which there are controversies in the literature. Variants include fibrous, giantcell, myxoid and inflammatory. ${ }^{2}$ The lung is the most common site of distant metastasis. Conservation surgery striving for nega- tive margins along with adjuvant radiation therapy is the treatment of choice for local disease. ${ }^{1}$ Distant metastasis, larger primary tumour $(>5 \mathrm{~cm})$ and highgrade tumour are all negative prognostic factors. ${ }^{3}$

Originally described by Mackenzie in $1886,{ }^{4}$ expectoration of large fragments of lung tumour is rare. ${ }^{5}$ It has been described in cases of endobronchial primary lung cancer and metastases from renal cell and colon carcinomas, osteogenic sarcoma and malignant melanomas. ${ }^{5}$ More recently in the era of AIDS, coughing up sections of tumour has been seen in patients with Kaposi's sarcoma and lymphoma. ${ }^{6}$ Spontaneous expectoration of metastatic malignant fibrous histiocytoma is exceptionally rare.

\section{Krishna B. Sharma}

Division of Respirology

University of Ottawa

Ottawa, Ont.

\section{References}

1. Zagars GK, Mullen JR, Pollack A Malignant fibrous histiocytoma: outcome and prognostic factors following conservation surgery and radiotherapy. Int 7 Radiat Oncol Biol Phys 1996;34(5):983-94.

2. Kearney MM, Soule EH, Ivins JC. Malignant fibrous histiocytoma: a retrospective study of 167 cases. Cancer 1980;45(1):167-78.

3. Gibbs JF, Huang PP, Lee RJ, McGrath B, Brooks J, McKinley B, et al. Malignant fibrous histiocytoma: an institutional review. Cancer Invest 2001;19(1):23-7.

4. Mackenzie GH. A practical treatise on the sputum. Edinburgh: $W$ \& AK Johnston; 1886. p. 50-1.

5. Kelly WF, Crawley EA, Vick DJ, Hurwitz KM. Spontaneous partial expectoration of an endobronchial carcinoid. Chest 1999;115:595-8.

6. Argyros GJ, Torrington KG. Fiberoptic bronchoscopy in the elevation of carcinoma metastatic to the lung. Chest 1994;105:454-7. 